Bangladesh J. Zool. 42(1): 1-10, 2014

\title{
ABUNDANCE AND DISTRIBUTION OF ENDOPARASITIC HELMINTHS IN ANABAS TESTUDINEUS (BLOCH, 1792) FROM A POLLUTED BEEL OF BANGLADESH
}

\author{
Aminul Islam Bhuiyan*, Jannatul Bushra and Osman Ghani \\ Department of Zoology, University of Dhaka, Dhaka-1000, Bangladesh
}

\begin{abstract}
Abundance and distribution of the endoparasitic helminths in Anabas testudineus (collected from a polluted water body) was analyzed. Out of 50 fish observed, $42(84 \%)$ were parasitized by at least one species. Five metazoan endoparasites, one trematode (Neopecoelina saharanpuriensis) and four nematodes (Ascaridida sp., Contracaecum sp., Camallanus anabantis and $C$. pearsei) were recorded. Prevalence was higher in female (90\%) hosts than males $(75 \%)$. A significant positive correlation was observed between the standard length of the host and the abundance for parasites except Ascaridida sp. Nematodes were the more prevalent group $(72 \%)$ than trematodes $(48 \%)$. No parasitic species was observed as central species category; three parasites $(N$. saharanpuriensis, Ascaridida sp. and Contracaecum sp.) were considered as secondary and Camallanus spp. as satellite species. All nematode parasites showed aggregated distribution pattern and the trematode showed random distribution pattern. Interspecies association between two species of parasite was low.
\end{abstract}

Key words: Endoparasitic helminths, Anabas tstudineus, abundance

\section{INTRODUCTION}

Aquatic pollution is still a problem in many freshwater and marine fauna. It causes negative effects on the health of the respective organisms (Fent 2007). The effects may manifest immediately (aquatic toxicity) or after prolonged exposure to the pollutant (chronic toxicity). Organisms such as fish try to avoid the uptake of pollutants by releasing their mucus from skin. However, this will be effective only in some cases. Usually pollutants are taken up by the gills or the intestine and accumulate until they reach a steady state concentration and then part of the substances will be excreted by the organism (Sures 2008). Part of the responses against pollutants and parasites are similar, whereas also parasite-specific host reactions occur. Parasite specific host reactions are defense mechanisms summarized as immune responses. But parasitic infection is also related to a general metabolic response as well as to physical damage of infected organs. Pollution and other man-made alterations of the aquatic

*Author for correspondence: <aminul_islam89@yahoo.com> 
environment may affect a parasite community directly by acting on the intermediate or the definitive host population (Poulin 1992). So parasites display individual, population and community level alterations in polluted environments (Marcogliese 2005).

Investigation of pollution effect on parasitic communities is scarce in Bangladesh, only Ghani et al. (2014) compared the community structure of endoparasitic helminths of Anabas testudineus from unpolluted and polluted sites of a freshwater body near Dhaka. Ghani and Bhuiyan (2011) worked on the community structure of endoparasitic helminths of Channa punctatus from a freshwater river and a polluted lagoon of Bangladesh. Parasites can also be used as an indicator for getting information about environmental pollution (MacKenzie 1999). The present work was undertaken to investigate the parasitic community of the host fish koi (Anabas testudineus) collected from a polluted Beel of Bangladesh.

\section{METRIAL AND METHODS}

The present study was conducted to investigate the parasites of host fish Anabas testudineus collected from Taiwabpur Beel, Board Bazaar, Ashulia industrial area, a branch of Turag River $\left(23^{\circ} 52^{\prime} \mathrm{N}\right.$ - 90 $\left.24^{\prime} \mathrm{E}\right)$ during AprilOctober, 2012. The water quality parameters of the sampling site were $\mathrm{pH}$ ranged of water was 6.14-8.79, hardness was high (300-1816 mg/1), turbidity level was 12.31-97.2 NTU, DO was quite low (0.76-7.1 mg/1), BOD was 0.7-4.65 $\mathrm{mg} / 1$ and $\mathrm{CO}_{2}$ was $0-15.5 \mathrm{mg} / 1$. The average width and depth of the river were $400 \mathrm{~m}$ and $10 \mathrm{~m}$ respectively.

Fifty koi fish (A. testudineus) were collected from local fishermen from its habitat as live and were immediately brought to the Parasitology Laboratory of the Department of Zoology, University of Dhaka for investigation. Sample size of each month was not equal since we could not collect same number of fish each month. However, monthwise sample size was: April- 9, May- 12, June- 12, July10, August- 4 and September- 3 fishes.

Investigation on helminth parasites: The examination was aimed to determine endoparasitic helminth infection of $A$. testudineus. Length, weight, sex and organwise infections of fish by each parasite species were recorded. Length and sex of hosts were noted before autopsy. All parasites from each organ were sorted, cleaned and counted and then preserved in $70 \%$ alcohol. Standard methods were used for staining and mounting. Under the dissecting microscope two species of Camallanus (C. anabantis, C. pearsei) looked similar. The morphological characteristics became apparent only when the parasites were studied under high magnification using a compound microscope. That is why 
these two species have been referred to as Camallanus spp. for calculation. One nematode, Ascaridida could not be identified to species level, therefore referred as Ascaridida sp.

Calculation and data analysis: To describe the structure of the infra- and component-communities, parasites' abundance, prevalence and intensity were calculated according to Bush et al. (1997). The methods used here was to describe general features of parasite infra-communities (prevalence, abundance, and intensity) and component community. Component community structure was described in two ways: traditional descriptors (e.g. mean abundance and mean intensity) and community similarity. Measurement of dominance, species richness and evenness were followed by standard definitions given by Begon et al. (1996).

Status of distribution: The classification was done according to the importance value of a parasite species for the community as- Central species $=$ present in more than 66.6\%; Secondary species $=$ present $33.3 \%-66.6 \%$ and Satellite species $=$ lower than $33.3 \%$ of the total number of fish analyzed (Bush and Holmes 1986).

Dispersion indices: Two criteria namely Green's dispersion index (GI) (Green 1966) and index of dispersion (DI) were used to evaluate the dispersion pattern of parasite species.

Evenness and equitability: The density of community depends on the number of species and the evenness. So an attempt was made to quantify the evenness component of the parasite diversity in the community. Three indices as Heip (1974) evenness index $\left(E_{h}\right)$, Hill (1973) evenness index $\left(E_{H}\right)$ and Modified Hill's ratio $\left(E_{H}^{\prime}\right)$ were used to determine species evenness.

Modified Hill's ratio $\left(E_{H}^{\prime}\right)$ is preferred over $E_{H}$ (Alatalo 1981) as it has a clearly desirable property for an evenness index.

Correlation: Pearson linear correlation coefficient $(r)$ and Spearman's rank correlation coefficient $\left(r_{s}\right)$ were computed to determine possible correlations between the host's standard length with the prevalence and abundance of each parasite species respectively (Zar 1996).

Existence of association: Jaccard's index (Jaccard 1908) was used to compare the presence/absence of two parasite species occurring in the same host at a time.

For determining the probable variation of infection in relation to host sex with abundance of parasite species Mann-Whitney ' $U$ ' test was conducted (Mann and Whitney 1947). 
The analysis included only component parasite species i.e. whose prevalence was greater than 10\% (Bush et al. 1990). Community structure of parasites has been determined as a function of host size and sexes. Statistical tests were conducted by using SPSS 16.0 software package. Statistical significance level adopted was $p \leq 0.05$.

\section{RESULTS AND DISCUSSION}

Component community structure : Altogether five helminth endoparasites were recorded during the present study. Out of the recorded parasites, one was digenea identified as Neopecoelina saharanpuriensis and four were nematodes as Ascaridida sp., Contracaecum sp., Camallanus anabantis and C. pearsei. Some $84 \%$ fishes were parasitized by one or more species of helminth endoparasites. From observation, it was found that infestation with trematode (48\%) was lower in contrast with nematode $(72 \%)$ endohelminths. Lower prevalence of trematode might be attributed to the cause that trematodes have a very complex life cycle and transmitted by means of interactions between prey-predator and presence or absence of snail community as an intermediate host for completing life cycle of these parasites (Marcogliese and Cone 1996).

In the host body, the most preferred habitat for these parasites was intestine. However, two nematodes (Ascaridida sp., Contracaecum sp) were also found in both intestine and stomach. Out of four parasites, the digenea $(N$. saharanpuriensis) and one nematode (Camallanus spp.) species were at their adult stage. Other two nematodes (Ascaridida sp., Contracaecum sp.) were at their larval stages (Table 1). Contracaecum sp. was relatively the most dominant species (36.78\% of all parasites) followed by Ascaridida sp. (25.29\%).

Table 1. Location of infection, developmental stage and dominance of parasites collected from $A$. testudineus

\begin{tabular}{llccccc}
\hline Name of parasite & $\begin{array}{l}\text { Location } \\
\text { of } \\
\text { infection }\end{array}$ & $\begin{array}{c}\text { Develop- } \\
\text { mental } \\
\text { stage }\end{array}$ & $\begin{array}{c}\text { No. of } \\
\text { infected } \\
\text { fish }\end{array}$ & $\begin{array}{c}\text { No. of } \\
\text { parasite }\end{array}$ & Ranges & $\begin{array}{c}\text { Relative } \\
\text { dominance }\end{array}$ \\
\hline $\begin{array}{l}\text { N. saharanpuriensis } \\
\text { Ascaridida } \text { sp. }\end{array}$ & $\begin{array}{l}\text { Intestine } \\
\text { Intestine, }\end{array}$ & Adult & 20 & 34 & $1-3$ & $19.54 \%$ \\
Lontracaecum $\mathrm{sp}$. & $\begin{array}{l}\text { Stomach } \\
\text { Intestine, }\end{array}$ & Larva & 24 & 64 & $1-3$ & $36.78 \%$ \\
Samallanus spp. & $\begin{array}{l}\text { Stomach } \\
\text { Intestine }\end{array}$ & Adult & 15 & 32 & $1-4$ & $18.39 \%$ \\
\hline
\end{tabular}

The occurrence of more parasites in the intestine than the stomach either might be due to the presence of digested food present there or due to greater surface area presented by the intestine (Adebanjo 1979). Smith (1981) reported that most parasites inhabit the intestine because of their general feeding habits. 
With the importance value based on prevalence only, Contracaecum sp. was considered the dominant species (50\%). According to status of distribution, Camallanus spp. accounted as satellite species and other three species as secondary species. In the sample, parasite species with higher mean intensity and abundance of Contracaecum sp. was $2.56 \pm 0.92$ and $1.28 \pm 1.44$, respectively (Table 2).

Table 2. Prevalence, mean intensity, mean abundance and status of helminth parasites of $A$. testudineus

\begin{tabular}{lcccc}
\hline Name of parasites & $\begin{array}{c}\text { Prevalence } \\
(\%)\end{array}$ & Mean Intensity \pm SD & $\begin{array}{c}\text { Mean Abundance } \\
\pm \text { SD }\end{array}$ & Status \\
\hline N. saharanpuriensis & 46 & $2.04 \pm 0.77$ & $0.94 \pm 1.15$ & Secondary \\
Ascaridida sp. & 36 & $2.44 \pm 0.86$ & $0.88 \pm 1.29$ & Secondary \\
Contracaecum sp. & 50 & $2.56 \pm 0.92$ & $1.28 \pm 1.44$ & Secondary \\
Camallanus spp. & 28 & $2.28 \pm 0.91$ & $0.64 \pm 1.14$ & Satellite \\
\hline
\end{tabular}

The high prevalence of Contracaecum sp. may be due to the fact that the intermediate host (usually copepode) being the main diet of A. testudineus. Esch et al. (1990) reported that the parasite community with its prevalence and intensity might be influenced by the age and length of the host, changes in the diet, in the volume of food ingested, ontogenetic changes in the immunocompetence and changes in probability of contact with intermediate hosts.

Infra-community structure: Parasites of A. testudineus had shown typical over dispersed type of distribution pattern (Table 3). Camallanus spp. showed the highest dispersion index value ( $\mathrm{DI}=2.031)$ suggested their highest clumping distribution $(\mathrm{d}=4.259)$ in the fish and the $\mathrm{d}$-value for Ascaridida sp. and Contracaecum sp. $(\mathrm{d}>1.96)$ also suggested aggregated pattern of distribution in the host body. N. saharanpuriensis $(\mathrm{d}<1.96)$ showed random pattern of distribution.

Table 3. Pattern of distribution of the metazoan parasites of A. testudineus

\begin{tabular}{lcccl}
\hline Name of parasite & DI & GI & d & Distribution type \\
\hline N. saharanpuriensis & 1.407 & 0.009 & 1.894 & Random \\
Ascaridida sp. & 1.891 & 0.021 & 3.764 & Aggregated \\
Contracaecum sp. & 1.620 & 0.010 & 2.751 & Aggregated \\
Camallanus spp. & 2.031 & 0.033 & 4.259 & Aggregated \\
\hline
\end{tabular}

$D I=$ Diversity index, $G I=$ Green's aggregate index, $\mathrm{d}=$ Statistical'd'value

Aggregated distribution of the parasite populations is considered as one of the most common features of metazoan parasite infections (Poulin 1993). In the present study, two aggregation measures were used: the variance-to-mean ratio (DI) and Green's dispersion index (GI). Values obtained from these two indices revealed a low aggregation level of distribution of the constituent parasite 
species. According to Anderson and Gordon (1982), this pattern of aggregate dispersion may have originated- (a) from the heterogeneity of the host's behavior; (b) by patterns of spatial aggregation in the distribution of infective stages; and (c) by the differences of susceptibility and capacity of the hosts' immunological reaction.

Simpson's index $(\lambda=0.265)$, Simpson's unbiased estimator $(\hat{\lambda}=0.261)$ and Shannon's index $\left(\mathrm{H}^{\prime}=1.357\right)$ indicated that this sample fishes were not infested by more parasites and the parasite community was poorly diverged. Evenness of parasite distribution was also counted with Heip evenness index $\left(E_{h}=0.962\right)$ and Hill's evenness index $\left(E_{H}=0.971\right)$ showed moderately higher value meant that community structure was well constructed by evenly distribution of all parasite species and well diverged (Table 4).

Table 4. Diversity and evenness measures of helminths endoparasite communities of $A$. testudineus

\begin{tabular}{lc}
\hline Diversity/Evenness indices & Values in the sample \\
\hline Simpson index $(\lambda)$ & 0.265 \\
Simpson unbiased estimator $\left({ }^{\hat{\lambda}}\right)$ & 0.261 \\
Shannon index $(H)$ & 1.357 \\
Heip evenness index $\left(E_{h}\right)$ & 0.962 \\
Hill's evenness index $\left(E_{H}\right)$ & 0.971 \\
Modified Hill's ratio $\left(E_{H}^{\prime}\right)$ & 0.961 \\
\hline
\end{tabular}

According to Sasal et al. (1999), the diet of the host species is the main factor affecting parasite community structure, especially for digenean trematodes that are transmitted to their final host through a predator-prey relationship. These authors proposed that hosts with a more diversified diet should encounter more intermediate host species and, consequently harbor more parasite species. Guégan et al. (1992) postulated that- (a) the diversity of endohelminths varies between sites or between species of hosts and; (b) the diversity of helminths is related to the size of the host, longevity and diet. They also claimed that size and diet together explain approximately $40 \%$ of the variance in the diversity of endohelminths of hosts. Therefore, it may be suggested that the feeding habit of A. testudineus was one of the most relevant factors for explaining the difference of endoparasitic diversity and richness of the fish community.

Infection in relation to host's standard length: According to Pearson's linear correlation coefficient and Spearman's rank correlation coefficients, all parasites showed positive correlation between host standard length and the prevalence of parasite but not significant. All parasites also showed significant positive 
correlation between host standard length and the abundance for all parasite species $(\mathrm{p}<0.01)$ except Ascaridida sp. (Table 5).

Table 5. Pearson's correlation coefficients $(r)$ and Spearman's rank correlation coefficients $\left(r_{s}\right)$ to evaluate the relationship between abundance and prevalence with the length of $A$. testudineus

\begin{tabular}{lcccc}
\hline Name of parasites & $\mathrm{r}$ & $\mathrm{p}$ & $\mathrm{r}_{\mathrm{s}}$ & $\mathrm{p}$ \\
\hline$N$. saharanpuriensis & 0.114 & 0.431 & 0.543 & $0.000^{* *}$ \\
Ascaridida sp. & 0.238 & 0.096 & 0.130 & 0.369 \\
Contracaecum sp. & 0.075 & 0.605 & 0.463 & $0.001^{* *}$ \\
Camallanus spp. & 0.481 & 0.461 & 0.461 & $0.001^{* *}$ \\
\hline
\end{tabular}

** Significance level $\mathrm{p}<0.01$

In the present study, host size was not always positively correlated with the prevalence and abundance of the parasite species, while at the infra-community level the total number of parasite individuals, in addition to their diversity and richness, generally presented positive relationships with host size. The presence of relationship between abundance and prevalence with the host's standard length might due to the presence of relationship between endoparasitic diversity and the body length of the host samples under analysis indicated that fish's growth rate did not vary according to their habitat. This fact indicates homogeneity in their increasing of body length during their life cycle and thus permits the uniform recruitment of the species of endoparasites throughout their life. As pointed out by Poulin (2000), these patterns cannot be generalized because in many host-parasite species systems the correlations are positive but weak and insignificant. Also ontogenetical changes in feeding behavior might influence parasite prevalence and abundance in the different host size classes (Saad-Fares and Combes 1992).

Infection in relation to host's sex: In the specimen (50 fishes), 30 were female and 20 were male of which 27 (90\%) female and $15(75 \%)$ male fishes were infected. According to the Mann-Whitney ' $\mathrm{Z}(\mathrm{U})$ ' test it was found that intensity of infection and parasite abundance was not significantly ( $p>0.05)$ affected to the host's sex (Table 6).

Table 6. Values of Mann-Whitney test, $Z(U)$ to evaluate the role of host sex and parasite abundance and prevalence in $A$. testudineus

\begin{tabular}{lcc}
\hline Name of parasite & $Z(\mathrm{U})$ & $\mathrm{p}$ \\
\hline$N$. saharanpuriensis & -0.485 & 0.628 \\
Ascaridida sp. & 0.267 & 0.789 \\
Contracaecum sp. & -0.505 & 0.614 \\
Camallanus spp. & -1.782 & 0.075 \\
\hline
\end{tabular}


The insignificant values with regard to host sex from Mann-Whitney test evidenced that the ecological relationships (occupation of habitat and diet) are similar among males and females. Same results have been obtained for other species of freshwater fishes (Janovy and Hardin 1988). Moreover, Poulin (1996) stated that high testosterone levels can cause immune-suppression in males and could lead in some cases to males suffering more from parasites than do females, although many parasite surveys have reported no significant differences in infection abundance and prevalence between female and male hosts.

In order to determine how often two or more species were found in same fish individual, Jaccard index (JI) was used to observe the interspecific association between each pair of parasite species. From the value of JI, it could be considered that interspecific association between two species of parasite was not so strong in this sample (Table 7). The positive association between species pairs, as observed indicates that the species coexist in the same host without competition with respect to ecological requirements, probably because they do not occupy the same niche along the digestive tract.

Table 7. Values of Jaccard's index (JI) to estimate interspecific association between each pair of parasite species of $A$. testudineus

\begin{tabular}{lcccc}
\hline Name of the parasites & $\mathrm{T} 1$ & $\mathrm{~N} 1$ & $\mathrm{~N} 2$ & $\mathrm{~N} 3$ \\
\hline$N$. saharanpuriensis (T1) & - & 0.250 & 0.485 & 0.296 \\
Ascaridida sp. (N1) & 0.250 & - & 0.273 & 0.143 \\
Contracaecum sp. (N2) & 0.485 & 0.273 & - & 0.522 \\
Camallanus spp. (N3) & 0.296 & 0.143 & 0.522 & - \\
\hline
\end{tabular}

Only one species pair of endoparasites presented a high associative degree (Contracaecum sp.-Camallanus spp.; JI=0.522) suggested their close association for sharing the same reservoirs/intermediate hosts. The lack of association among other endoparasites suggested that its intermediate hosts were not simultaneously ingested by the fish and thus they constitute different items in its diet. We were concerned with how often two species were found in same location. This affinity (or lack of it) for coexistence of two species is referred to as interspecific association. In general, an association between two species exists because: (a) both species select or avoid the same habitat or habitat factors; (b) they have the same general abiotic and biotic environmental requirements; or (c) one or both of the species has an affinity for the other, either attraction or repulsion. However, these data from quantitative associations between parasite species could be used with caution to explain the parasite community structure. 


\section{LITERATURE CITED}

ADEBANJO, A.O. 1979. A survey of parasites of Clarias lazera in Dundaye area of Rima River, Sokoto, Project submitted to Zoology Unit of Biological Science, Usman Danfodio University, Sokoto, October, 1977 (ADM NA2052).

ALATALO, R.V. 1981. Problems in the measurement of evenness in ecology. Oikos. 37: 199-204.

ANDERSON, R.M. and GORDON, D.M. 1982. Processes influencing the distribution of parasite numbers within host populations with special emphasis on parasite-induced host mortalities. Parasitology. 85: 373-398.

BEGON, M., HARPER, J.L., and TOWNSEND, C.R. 1996. Ecology: Individuals, populations and communities. 3rd edition. Blackwell Science, Oxford, U.K. pp. 686-692.

BUSH, A.O. and HOLMES, J.C. 1986. Intestinal helminths of lesser scaup ducks: An interactive community. Can. J. Zool. 64: 142-152.

BUSH, A.O., AHO, J.M. and KENNEDY, C.R. 1990. Ecological versus phylogenetic determinants of helminth parasite community richness. Evolutionary Ecology. 4: 1-20.

BUSH, A.O., LAFFERTY, K.D., LOTZ, J.M. and SHOSTAK, A.W. 1997. Parasitology meet ecology on its own terms: Margolis et al. revisited. J. Parasitol. 83(4): 575-583.

ESCH, G.W., SHOSTAK, A.W., MARCOGLIESE, D.J. and GOATER, T.M. 1990. Patterns, and processes in helminth parasite communities: an overview. In ESCH, GW., BUSH, AO. and AHO, J. (Eds.). Parasite communities: patterns and processes. New York: Chapman and Hall. pp. 1-19.

FENT, K. 2007. Permanent fish cell cultures as important tools in ecotoxicology. Altex. 24: 26-8.

GHANI, M.O., BHUIYAN, A.I. and BUSHRA, J. 2014. Community structure analysis of endoparasitic helminths of Anabas testudineus from unpolluted and polluted sites of a freshwater body of Dhaka. The Dhaka Univ. J. Biol. Sci. 23(1): 27-38.

GHANI, M.O. and BHUIYAN, A.I. 2011. Community structure of endoparasitic helminthes of Channa punctatus from a fresh water river and a polluted lagoon of Bangladesh. Bangladesh J. Zool. 39(2): 173-185.

GREEN, R.H. 1966. Measurement of non-randomness in spatial distributions. Researches Population Ecology. 8:1-7.

GUÉGAN, J.F., LAMBERT, A., LÉVÊQUE, C., COMBES, C. and EUZET, L. 1992. Can host body size explain the parasite species richness in tropical freshwater fishes? Oecologia. 90: 197-204.

HEIP, C. 1974. A new index measuring evenness. J. Mar. Bio. Assoc. 54: 555-557.

HILL, M.O. 1973. Diversity and evenness: a unifying notation and its consequences. Ecology. 54: 427-32.

JACCARD, P. 1908. Nouvelles recherches sur la distribution florale. Bull. Soc. Vaud. Sci. Nat. 44: 223-270.

JANOVY, J. and HARDIN, E.L. 1988. Diversity of the parasite assemblage of Fundulus zebrinus in the Platte River of Nebraska. J. Parasitol. 74: 207-213.

MacKENZIE, K. 1999. Parasites as pollution indicators in marine ecosystems: a proposed early warning system. Marine Pollution Bulletin. 38: 955-959.

MANN, H.B. and WHITNEY, D.R. 1947. On a test of whether one of two random variables is stochastically larger than the other. Ann. Math. Statist. 18: 50-60.

MARCOGLIESE, D.J. 2005. Parasites of the superorganism: are they indicators of ecosystem health? Int. J. Parasitol. 82: 389-399. 
MARCOGLIESE, D.J. and CONE, D.K. 1996. On the distribution and abundance of eel parasites in Nova Scotia: influence of $\mathrm{p}^{\mathrm{H}}$. J. Parasitol. 82: 389-399.

POULIN, R. 1992. Toxic pollution and parasitism in freshwater fish. Parasitol. Today. 8: 58-61.

POULIN, R. 1993. The disparity between observed and uniform distributions: a new look at parasite aggregation. Int. J. Parasitol. 23(7): 937-944.

POULIN, R. 1996. Helminth growth in vertebrate hosts: does host sex matter? Int. J. Parasitol. 26: 1311-1315.

POULIN, R. 2000. Variation in the intraspecific relationship between fish length and intensity of parasitic infection: biological and statistical causes. J. Fish. Biol. 56(1): 123-137.

SAAD-FARES, A. and COMBES, C. 1992. Abundance/host size relationships in a fish trematode community. J. Helminthol. 66(1): 87-192.

SASAL, P., NIQUIL, N. and BARTOLI, P. 1999. Community structure of digenean parasites of sparid and labrid fishes of the Mediterranean Sea: a new approach. Parasitol. 119: 635-648.

SMITH, A.C. 1981. Introduction of Parasitology. Willey New York. pp. 822.

SURES, B. 2008. Environmental Parasitology. Interactions between parasites and pollutants in the aquatic environment. Journal of Helminthology. 15: 434-438.

ZAR, J.H. 1996. Biostatistical Analysis, 3rd ed., Prentice Hall, Inc., Upper Saddle River, New Jersey. pp. 662. 